\title{
Digital world: Case Study from Universitas Terbuka's MOOCs Parenting Course
}

\author{
Siti Aisyah, Dian Novita, Della Raymena Jovanka \\ Universitas Terbuka, Indonesia \\ e-mail: $\underline{\text { sitisavira@unesa.ac.id }}$
}

\begin{abstract}
MOOCs is a new way of learning for Indonesian citizen as it enables universities and institutions to share their best knowledge to everyone. This paper aims to describe Universitas Terbuka's (UT) efforts to provide a solution in the limited access and quality of education by providing various free courses to public through MOOCs, especially in Parenting field. MOOCs is an online course that is open and can be followed by unlimited number of participants. Because of its unlimited, MOOCs can provide an opportunity to anyone around the world to interact with each other. Interactions can occur among participants from around the world and the teachers. Two major problems of education in Indonesia consist of: first, the access of the course that includes the availability and affordability. The second issue is about the teacher's limitation, infrastructure, and good governance. Advances in technology and innovation in information technology area has brought an ubiquitous phenomenon which is required in the world of education, can be obtained instantly, without having to build physical infrastructure of the school. This phenomenon has been utilized by many countries, including Indonesia, to provide educational services in massive, open to anyone, as long as they have access to the Internet. Through Massive Open Online Course (MOOCs), individuals can join any courses without having to enroll as student in a university or institution. UT's MOOCs in Parenting topic was launched on March 13, 2016 as part of a global movement "Open Education Week". For UT, MOOCs program is one of realization of its mission to build a culture of lifelong learning. In addition, MOOCs is an opportunity to introduce UT to the wider community with the provision of free quality knowledge. MOOCs of UT are now still using Bahasa, considering that until now they are dedicated to all the Indonesian people. MOOCs of UT are developed by using open source platform that is Moodle, considering that the lecturers and tutors previously have using the similar platform for their formal courses. Their capabilities and sufficient skills in using this platform is believed will facilitate their interaction with MOOCs' students as well. The structure of UT's MOOCs Parenting consist of: 3 lecturers, length of course is 8 weeks, 3 assignments, 6 OERs, and some discussions. Participants will receive useful information on how to educate children well, through interaction among participants and with their lecturers.
\end{abstract}

Keywords: digital world, MOOCs, parenting, open educational resources, Universitas Terbuka

\section{INTRODUCTION}

The rapid development of information technology resulted in the launch of new breakthroughs offered, including in the world of education. One form of technology that supports the world of education is Massive Open Online Courses
(MOOCs). MOOCs are a form of technology-based education that is increasingly being used by the wider community in the world. In Indonesia alone online courses are not too popular, because in Indonesia lectures or face-to-face training are still a culture. Whereas MOOCs are essentially online lectures or trainings that involve many participants, 
are interactive, affordable and inexpensive and can even be free and can meet the needs of society widely. MOOCs give participants the freedom to choose topics according to the area of interest. MOOCs also make it easy for participants who have the desire to learn but are constrained by time, effort, opportunity and costs.

Through MOOCs, individuals can take courses without having to register as a student at a university or institution. This paper will explore the efforts of Universitas Terbuka to provide solutions by providing educational services in a transparent and open way to improve the quality of education, especially early childhood education through providing Moocs on the topic of parenting.

Since 2017, the Universitas Terbuka provides Moocs Parenting services, which discuss about how parents develop children's potential by creating a safe and friendly environment for the growth and development of their beloved sons and daughters. The dish is equipped with practical tips, expert opinions and examples are packaged in multimedia. The competencies expected by participants after participating in this program are that participants can meet the needs of children based on their potential, provide protection and educate children in their daily lives properly so that your child can grow and develop optimally.

Based on the questionnaire that had been given by the participants during registration 2107 with the number of 114 participants obtained the following data. $62 \%$ are women and $38 \%$ are men. While the educational background is high school: 44\%, Diploma 18\%, S1: $31 \%$ and S2: 8\%. Participants' work is known to students: $18 \%$, private: $42 \%$, selfemployed: $4 \%$, PNS $13 \%$ and others $23 \%$. Another interesting thing about how they get information about Moocs parenting organized by UT is data that through UT websites as much as $68 \%$, social media $14 \%$, google / other search engines $12 \%$ and friends as much as $6 \%$. The aim of the participants to follow Mooc is $75 \%$ because they want to increase their knowledge and $22 \%$ because they expect to get a certificate.

Based on these data it can be seen that the public interest in following Moocs still needs to be improved. MOOCs as mean of learning by using digital mean is expected to contribute to the improvement of 21st century skills, especially in digital literacy (ICT). For this reason, efforts are needed to increase the number of participants and the development of Moocs material needs to be well prepared by displaying material that is easy to understand, interesting by displaying Open Educational Resources (OER) so that participants will gain complete and integrated knowledge.

This article describes the efforts that have been made by Universitas Terbuka in developing learning models through Moocs Parenting in order to strengthen participants 'knowledge of the care of their children so that children can grow and develop optimally and increase participants' awareness about the benefits of digital literacy as a basic literacy (life skills ) towards the 2045 golden generation.

\subsection{Literature Review}

MOOCs is a model for delivering online learning content to everyone who wants to take a course and be carried out openly. The MOOCs organizer can get a college or other accredited institutions. The term MOOC first appeared in 2008 by Dave Cormier of the University of Prince Edward Island after joining the Connectivism and Connective Knowledge course (CCK08). The course was initially attended by 24 students from the University of Manitoba who had previously paid to take a course. But then offered for free as an open online course and followed by more than 2,200 students. Currently MOOC has several types that can be classified as xMOOC, cMOOC, and quasiMOOCs. xMOOCs comes from regular university courses such as Stanford (Coursera), MIT (Massachusetts Institute of Technology), Harvard (edX), and Udacity. xMOOC began in 2011 with a form of pedagogy that supports this program, namely teachers as educators and students as participants. At Course is offered with learning videos that range between 15 and 30 minutes. cMOOC is based on a form of connectivity pedagogy. Participants can determine for themselves how and in what ways they follow. The main element in cMOOCs is sharing knowledge with others to connect with each other. Unlike xMOOCs, cMOOCs are mostly open in terms of participant activities. If they are active, they can create additional material, such as blog posts, tweets, videos, or podcasts. In this way, a connection between participants or connectivity is formed. Prefix c on cMOOC is taken from a connectivismbased approach. Finally, quasi-MOOC which provides web-based tutorials that can be accessed freely and openly for learning, teaching and research. A quasi-MOOC example is Khan 
Academy and MIT Open Course Ware (OCW). This learning model is intended to support specific learning tasks such as operations in algebra, or they are treated as learning resources that do not offer social interactions such as cMOOCs. (http://ejournal.upi.edu/index.php/pedagogia/article/ download/3382/2374)

The platform used for MOOCs is now very diverse, but basically they have 4 fundamental characteristics, namely

1. Massive, MOOCs have the principle of infinite scalability, meaning that the scale is unlimited. The number of MOOCs participants can reach hundreds of thousands of people for each lecture. This is because technically, there are no obstacles that can limit the number of participants, as long as participants can connect to the internet.

2. Open, There are no specific requirements to follow MOOCs. All that is needed is a device to access it (computer or mobile device) and internet connection. In addition, some MOOCs are offered free of charge as held by Universitas Terbuka, some only charge fees for the process of evaluating learning outcomes and certificates that will be received by participants; and others set certain fees to follow MOOCs. Only six Indonesian online lecture sites (MOOC) actually provide free content, namely: Universitas Terbuka MOOCs, CodeSaya, FOCUS Fisipol UGM, IndonesiaX, Sibejoo and UCEO Ciputra University

3. Online, Universitas Terbuka provides MOOCs services as part of learning services with open and distance learning systems. Universitas Terbuka provides MOOCs material through the Moodle platform, then participants use the material, in the form of reading material, videos and quiz questions or assignments, exercises and discussions. Topics of Universitas Terbuka MOOCs are Parenting, Public Speaking, ASEAN Studies, Introduction to Moodle, Food Processing, Marketing Management, and Distance Education through MOOCs.

4. Courses, Learning held by MOOCs is managed as a whole learning. Designed according to purpose, this learning also requires participants to read initiation materials, listen to the videos that are included, and also take quizzes and do the assignments. Participants are also encouraged to engage in online discussions in the forums provided. Participants can also get a certificate if they have completed the learning that can be downloaded by the participants themselves.
MOOCs Parenting currently includes videos taken from other sources, not the work of curator. Some videos still use English, which is certainly still an obstacle for participants who do not master English well. It is necessary that the video is the work of curator, so that it can reach all circles and can be more easily understood.

Weller (2014) stated that MOOCs, because of their emerging nature, need research on how to produce and provide open courses that reuse materials in the OER format.

MOOC, which is a type of OER is an online course open to anyone to access, free of fees, unlimited participation (Pujar \& Bansode, 2014; Spector, 2014) and has accessibility and flexibility as the main features (King et al., 2014; Parkinson, 2014).

The term MOOC was created by Dave Cormier and Bryan Alexander (Iqbal et al., 2014; Stuchlíkova \& Kosa, 2013) to describe a course called "Connectivism and Connective Knowledge" in 2008 as an experimental method to test Connectionist Learning Theory proposed by George Siemens and Stephen Downes (Eckerdal et al., 2014).

In the past 8 years, MOOC has become a new wave of online learning. MOOC was one of the innovations that emerged from the movement of Open Educational Resources (OER) in 2008. OER is defined as all types of educational materials in the public domain, or released with an open license, which allows participants to legally and freely use, copy, adjust, and share again. A broad, free and quality information sharing spirit that is the forerunner of the emergence of free courses around the world, with the Massachusetts Institute of Technology (MIT) as a pioneer in the use of educational learning resources that are open to anyone with the launch of MOOCs in 2011 (UNESCO, taken from http://www.unesco.org).

Universitas Terbuka (UT) was founded in 1984 with the aim of expanding access to higher education in Indonesia. As only one State University (PTN) in Indonesia that uses open and long distance learning, UT has more than 350,000 active students, UT is classified as "Top Ten Mega University of The World". UT is a member and founder of "The Global Mega-University Network (GMUNET). GMUNET was founded in 2003 as a network of colleges consisting of universities with more than 100,000 students (https://id.wikipedia.org, 2016). 
One of the study programs in UT which has the second largest number of students after the PGSD Study Program is the Early Childhood Education Study Program. The followings registration data are:

\begin{tabular}{lllll}
\hline Registration & 2016,1 & 2016,2 & 2017,1 & 2017,2 \\
period & 58,193 & 51,360 & 46,900 & 44,105 \\
\hline
\end{tabular}

With a large number of students, indicating that Indonesian people need in-depth knowledge of early childhood education. Especially if it is associated with children who are currently studying in PAUD education units, then by 2045 will be the future leader of the nation, so it is right now that we are educating the Golden Generation of 2045.

Submission of information about how to educate early childhood can be done in various ways, both through formal education strata such as the PGPAUD S1 Program for teachers, which is equally important is education for parents. To them must be conveyed how good parenting, so that their children can grow and develop optimally. Parenting mistakes made by parents can result in children not being able to go through the process of their growth comfortably, pleasantly and ultimately result in the child not being able to bring up his potential.

MOOCs Perenting whose management is under the PGPAUD UT S1 Study Program, recognizes the importance of parents being given knowledge and tips on how they can provide good care for their beloved sons. Currently the Parenting MOOCs material contains information about Playing. As parents or other educators, participants are given the knowledge that playing has an important function for children. Playing becomes a child's favorite activity as well as a way to increase knowledge in various levels. Playing is also a means for children to develop, as well as their development detectors. So parents need to have a proper understanding of this and need to develop play activities for our children. Of course, theoretical studies need to be explored to establish the concept of playing. After learning the material the participants were asked to express their opinions through the conclusions and one of the OERs given was about Traditional Games, to restore the preoccupation of playing in the past and transmit that preoccupation to the beloved son. Besides that, it was also given about how to manage playing time and video presentation of The Power of Play Based Learning that is followed by giving assignment.
Subsequent material on Discipline. The material begins with the delivery of the nature of discipline, tips and videos about disciplinary practices that are very useful for parents and continued with discussion. The discussion was quite active and was carried out by the participants and participants shared their experiences about the discipline that was applied and the experience that they passed during their childhood. The discussion took place warmly with moderators by the MOOCs Curators.

\section{METHOD}

In its development the parenting class uses the Research and Development method of Borg \& Gall (development research) which combines Borg \& Gall (1989) with Borg \& Gall (2007).

Detailed explanations made at each step are as follows.

1. Research and collect information (research and information collecting). This step was carried out by conducting preliminary research through surveys, then making a needs analysis to see the gap between das sollen and das seign, so that the activities that must be developed are also adapted to a clear scientific basis through literature review. The survey results in the field will be analyzed using reference theories, and if there is a gap between the two, a revision is made as to the development of further activities.

2. Identify learning objectives. This is done by determining the general competencies that children will be able to master after learning. This step is much shorter than making a needs analysis, because it is the first step.

3. Conduct analysis of learning. Learning analysis is carried out by describing general competencies into specific sub-competencies or competencies and identifying the relationship between specific competencies with each other.

4. Analyze participants and their context. This step is done by identifying the behavior and initial characteristics of the participants, by approaching the participants as they are to find out the competencies of the participants before taking part in the learning.

5. Write down the operational objectives of learning. This step is intended to write specific measurable instructional goals from participants, which ideally have four 
components, namely Audience (A), Behavior (B), Condition (C) and Degree (D).

6. Develop assessment instruments. This step is a way to develop an assessment tool for the learning process, to determine the extent to which MOOCs participants can absorb the material presented. This assessment is integrated in the MOOCs application learning.

7. Develop strategies. This step is in the form of a sequence of instructional activities associated with the method, a medium that can be used as a delivery pattern for MOOCs materials.

8. Develop and select teaching materials. Learning materials made will be adjusted to the instructional approach from the previous step. Learning material consisting of initiation materials and learning videos that will strengthen participants in understanding the material of the Parenting MOOCs materials.

9. Design and carry out formative evaluation in learning. Formative evaluation is intended to revise the development of the model to be used. The four ideal stages of formative evaluation are as follows: (1) review of instructional content by content experts outside members of the design team, (2) one-on-one evaluation involving 3 participants, (3) small group evaluations involving 8-15 and (4) field trials involving more than 30 participants. Each stage is followed by activities to revise MOOCs before carrying out the next stage.

10. Revise learning, based on formative evaluations that have been carried out. This step is an improvement of research products based on the results of trials in the field. All inputs in the form of feedback in oral and written form are used as material to improve the model. So at this stage a revised model will be generated based on input from field trials.

The data collection used in this study was in the form of questionnaires distributed to participants contained in the moodle application with questions including: how is the delivery pattern of MOOCS material that can strengthen participants in providing care for children?

In order to answer research questions, the data collection techniques that will be used are more indepth interviews with experts in this regard parenting experts and ICT experts as well as instructional design and participants to get an overview of the application of the Parenting MOOCs model. The development of initiation material in the form of videos will be evaluated based on the input of experts and participants. Detailed data collection and analysis can be presented in the following table.

\section{DISCUSSION}

1. Gender

It can be seen from 114 participants who participated in MOOCs that there were more women, namely 71 participants, while male participants who attended online lectures were 43 participants. So it can be said that the information needs about parenting for children are needed more by women to help them care for children at home, while men attend these online lectures to add their insight related to the care of their children.

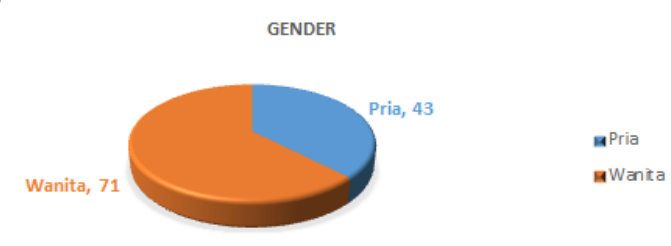

2. Education Background

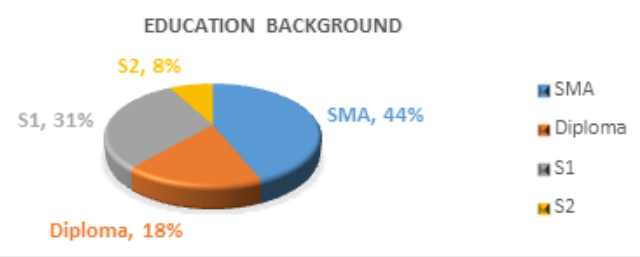

The education of participants who took part in the online lecture was very diverse. It can be seen that the highest number of participants who participated in the lecture were high school graduates, that is $44 \%$. This is because they are fresh graduates where they are looking for as much information as possible to continue their studies at the undergraduate program where if they can attend this short course well they can enter the early childhood education teacher education program (PGPAUD) owned by the Universitas Terbuka, followed by participants who have the latest education undergraduate viz. as much as $31 \%$, then those with a diploma background as much as and $18 \%$. And the last one with a post-graduate background is $8 \%$. 


\section{Occupation}

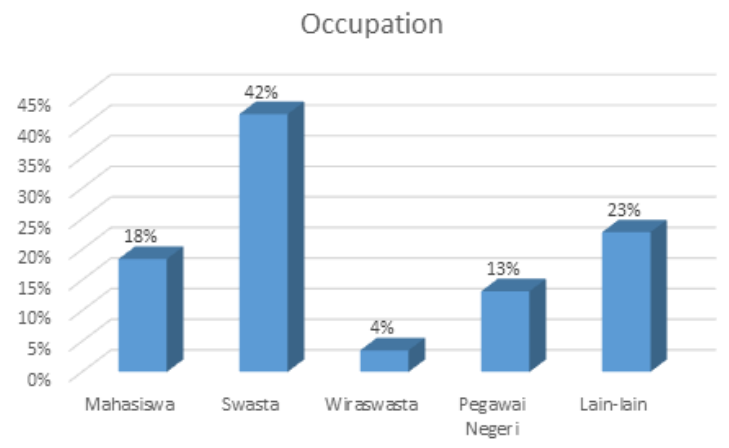

The highest average occupation of those who attend this online course is Private, which is $42 \%$, while the other $23 \%$ are having other jobs, those are teachers, housewives, school administration, principals and posyandu lady activists, for civil servants who most of these online lectures are teachers as much as $13 \%$, while students of programs for early childhood education only as much as $18 \%$ who attend this lecture and as much as $4 \%$ are they have jobs as private employees.

4. Information Sources about online open courses (MOOCs)

Most of the participants who attended the MOOCs got information about this lecture from websites owned by Universitas Terbuka which were $68 \%$, while those who obtained information from social media were $14 \%$, those who obtained information from Google were 12\%, and 6\% they get from friends during the tutorial. This shows that the digital literacy of participants is good, where only around $6 \%$ get information off line, while the remaining $94 \%$ search through online media. This is quite encouraging for the community's ability to find information through online channels.

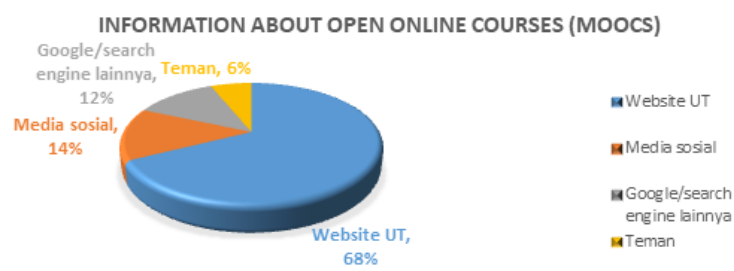

5. Experience previously in attending online open lectures (MOOCs)
JOINED EXPERIENCE IN MOOCS PREVIOUSLY

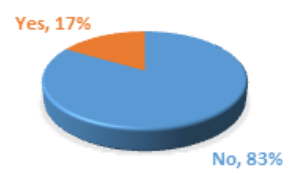

In the table above it can be seen that participants who had attended online lectures before they followed Moocs were 17\% smaller than those who had never attended other lectures when participating in Moocs online lecture which was $83 \%$.

6. The purpose of attending online open courses (Moocs)

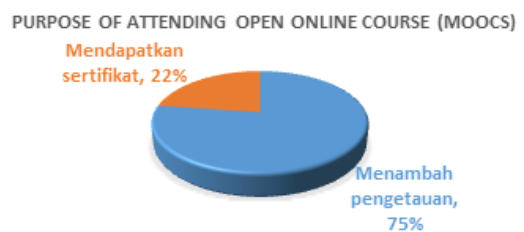

From the table above it can be seen that participants who attend online open lectures wanted to increase their views in natural care for their children, $75 \%$ of them is greater than those who only attend online open courses to get certificates only. This data shows that the community is very eager to get knowledge from various sources, one of them through Moocs. This opportunity encourages developers to be able to provide the best material in order to increase public knowledge of the importance of educating and caring for children properly in accordance with the principles of psychology and early childhood education.

7. Devices used to attend online open courses

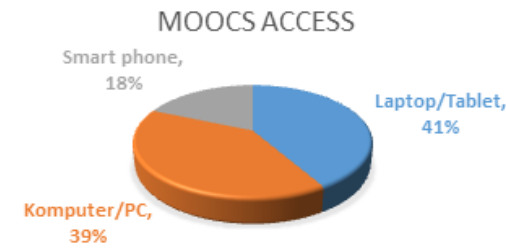

The table above explains that to access online open lectures (MOOCs) participants use more laptops / tablets in the amount of $41 \%$ and those who use computers / PCs are 39\%. Then participants who attend online lectures using smart phones by $18 \%$. Information this illustrates that the community has seen that the devices not only can be used to communicate but also has added value to be able to 
learn anywhere at any time adjusted to their respective abilities.

8. Courses followed in accordance with expectations

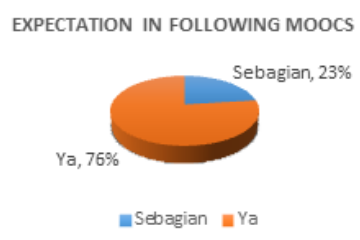

Participants who stated that their expectations in joining this online lecture were met can be seen in the table above that is as much as $76 \%$. Because actively participating in the MOOCs lectures until they get a certificate, participants can attend lectures in the teacher education program for early childhood education, while those who feel part of their expectations are fulfilled, it seems $23 \%$ is because they hope to be released one semester to attend lectures in the $\mathrm{S} 1$ program PGPAUD UT.

9. The goal of following Moocs is achieved ACHIEVEMENT IN FOLLOWING MOOCS

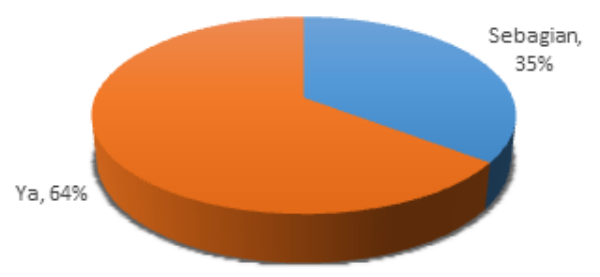

asebagian $\mathbf{n}$ Ya

It was seen that $35 \%$ of participants who felt their purpose was achieved when attending the Moocs Online course, but of all the participants turned out to be $64 \%$ felt their desired goal was achieved when attending this MOOCs lecture. This can help them attend the next lecture at the undergraduate level, at the PGPAUD UT program.

10. Take another online open course (MOOC) in the future

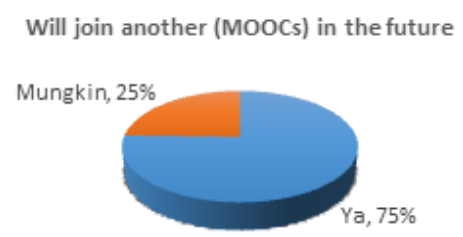

a $\mathbf{\text { Mangkin }}$
As many as $75 \%$ of participants who stated their goals and expectations were achieved said they were very enthusiastic in taking part in online lectures given by Universitas Terbuka and would take part in online lectures at other times that would come with different topics and themes, while participants who said they might attend online lectures provided by the Universitas Terbuka as much as $25 \%$ if the topic given is in accordance with the information they need.

11. If you can get credit (SKS) for the course you are taking, are you interested in?

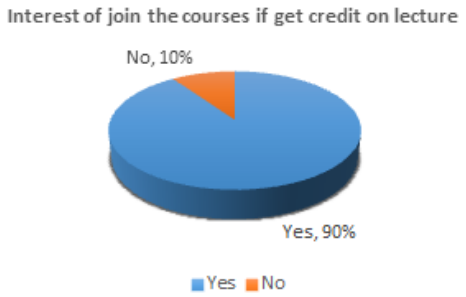

Participants who said they were very interested in participating in the online lecture given if there was a positive impact on the freeing of credits in the courses that were followed by $90 \%$, but $10 \%$ said they were not interested in because they attended this online lecture just to increase their insight in childcare.

12. If UT can acknowledge this course for a degree program, are you interested?

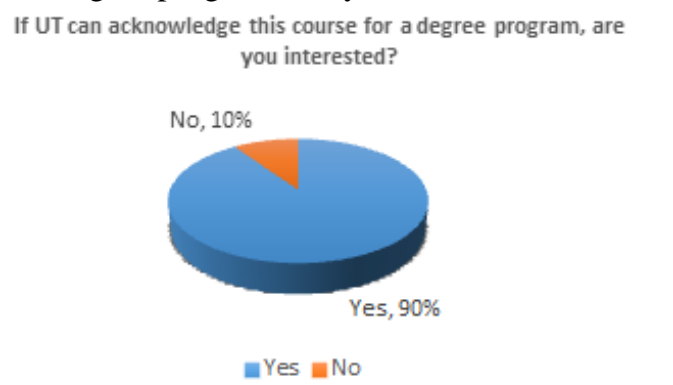

It can be seen in the table that as many as $90 \%$ of online lecture participants said they were interested in if this course was recognized for the undergraduate program that was followed or there were exemptions for subjects related to the subject in the undergraduate program whereas it was seen that only $10 \%$ of participants said they were not interested in if UT acknowledged this course for degree program. 


\section{CONCLUSION}

Most of MOOCS participants are women, who have a high school education background, as many as $44 \%$ are fresh graduate in completing formal education, on average those who are interested in attending lectures at UT are those who want to study while working and most of them work in private that is $42 \%$. The source of information they found to attend online lectures was from the Universitas Terbuka website, the rest they got information from friends and social media.

Participants who attended the MOOCs lecture on average had never attended online lectures before, and most of the $75 \%$ attending this lecture were to add insight into attending long distance lectures at Universitas Terbuka, they were also accustomed to accessing online lectures using laptops. So that the courses they follow are as expected as they want to continue to study programs in accordance with their interests, because their achievements are achieved, their goals for attending the study are also gained. So that they hope to be able to attend lectures held by Universitas Terbuka on different topics.

Participants also stated that by following Moocs their knowledge of parenting that is in accordance with scientific principles is increasing. This can be proved by the participant's statement that a portion was achieved as much as $35 \%$ when attending the Moocs Online lecture, but $64 \%$ of all participants felt that the goal they wanted was achieved when attending this MOOCs lecture.

With the achievement of their goals and expectations, their wishes are also great if the certificates and subjects they follow can be recognized as credits (SKS) for related subjects in the PGPAUD study program they will follow. If UT recognizes these courses as credits (SKS), it is desirable for them to enrol the study program belongs to UT.

\section{REFERENCES}

[1] Eckerdal, A., Kinnunen, P., Thota, N., Nylen, A., Sheard, J., \& Malmi, L. (2014). Teaching and learning with MOOCs: Computing academics' perspectives and engagement. 2014 Innovation and Technology in Computer Science Education Conference, ITICSE 2014, Uppsala. $\mathrm{G}$

[2] Iqbal, S., Zang, X., Zhu, Y., Chen, Y. Y., \& Zhao, J. (2014). On the impact of MOOCs on engineering education. 2014 IEEE International Conference on MOOCs, Innovation and Technology in Education, IEEE MITE 2014.

[3] King, C., Doherty, K., Kelder, J.-A., McInerney, F., Walls, J., Robinson, A., \& Vickers, J. (2014). «Adecuacion al proposito»: un enfoque centrado en el colectivo de estudiantes para el diseno de un curso en línea masivo y abierto (MOOC). RUSC Universities and Knowledge Society Journal, 11(3), 113127. K

[4] Parkinson, D. (2014). Implications of a new form of online education. Nursing Times, 110(13), 15-17.

[5] Pujar, S. M., \& Bansode, S. Y. (2014). MOOCs and LIS education: A massive opportunity or challenge. Annals of Library and Information Studies, 61(1), 74-78. R

[6] Spector, J. M. (2014). Remarks on MOOCS and Mini-MOOCS. Educational Technology Research and Development, 62(3), 385-392. S

[7] Stuchlíkova, L., \& Kosa, A. (2013). Massive open online courses - Challenges and solutions in engineering education. 11th IEEE International Conference on Emerging eLearning Technologies and Applications, ICETA 2013, Stara Lesna.

[8] Weller, M. (2014). The battle for open: How openness won and why it doesn't feel like victory. Ubiquity Press. Retrieved from http://www.oapen.org/search?identifier=533876 